\title{
Pontos e contrapontos no desenvolvimento da interdisciplinaridade na formação técnica em enfermagem*
}

\author{
Points and counterpoints in the development of interdisciplinarity in nursing technical training \\ Puntos y contrapuntos en el desarrollo de la interdisciplinariedad en la formación técnica \\ en enfermería
}

Como citar este artigo:

Fontana PM, Pinto AAM, Marin MJS. Points and counterpoints in the development of interdisciplinarity in nursing technical training. Rev Esc Enferm USP. 2021;55:e03771. https://doi.org/10.1590/S1980-220X2020025703771

\section{Patricia Maia Fontana ${ }^{1}$ \\ Adriana Avanzi Marques Pinto \\ Maria José Sanches Marin ${ }^{3}$}

* Extraído da dissertação: "Pontos e contrapontos da implementação da interdisciplinaridade na formação técnica em Enfermagem", Faculdade de Medicina de Marília, 2020.

${ }^{1}$ Faculdade de Medicina de Marília, Programa de Pós-Graduação Mestrado Profissional, Marília, SP, Brasil.

${ }^{2}$ Fundação Educacional do Município de Assis, Departamento Enfermagem, Assis, SP, Brasil.

${ }^{3}$ Universidade Estadual Paulista,

Departamento de Pós-Graduação em

Enfermagem, Botucatu, SP, Brasil.

\begin{abstract}
Objective: To characterize the points and counterpoints in the development of interdisciplinarity in the nursing technical training. Method: This is an exploratorydescriptive study with a qualitative approach conducted through interviews with 30 teachers and coordinators of nursing technical courses from 12 different regions of the state of São Paulo. Data analysis was performed through theme-based content analysis. Results: Regarding the theme of institutional orientation, it was found that, although there are initiatives to promote interdisciplinarity, since there is teacher training and definition of goals for articulation with other courses and for the joint work among the teachers of the disciplines, these are still vague and ineffective. As for the theme, the implementation of interdisciplinarity by the teachers, it is observed that they seek different forms of integration, but they come across the curricular structure, the form of teacher hiring, and the resistance to changes. With respect to the comprehension of the concept, relevant aspects of its meaning are recognized; however, they admit the existence of limits. Conclusion: The institution defines a trajectory aiming at interdisciplinarity, the teachers try to follow the path for its implementation; however, they find structural obstacles, little comprehension of the concept, and resistance to changes. It appears that efforts are needed to advance the curricular implementation with the logics of interdisciplinarity.
\end{abstract}

\section{DESCRIPTORS}

Interdisciplinary Placement; Education, Nursing, Associate; Health Human Resource Training. 


\section{INTRODUÇÃO}

O trabalho em saúde, seja qual for o cenário, é essencialmente relacional e revestido de subjetividade, exigindo dos profissionais competências específicas e uma formação de qualidade, de forma a serem percebidos como protagonistas de saberes e práticas transformadoras no seu espaço de trabalho. Entretanto, mesmo com algumas políticas direcionadoras, observa-se a inadequação na formação profissional ${ }^{(1)}$.

Nesse contexto, a formação de profissionais de Enfermagem do nível médio reveste-se de grande importância, por representar um grande contingente de profissionais da área da saúde da linha de frente do cuidado, que mantém contato direto com os usuários e, portanto, com grande responsabilidade na qualidade da assistência prestada.

Nas últimas décadas, alguns movimentos nacionais têm buscado direcionar essa formação com vistas a atender às necessidades sociais e do mercado de trabalho. A Lei no 9.394 de 1996 das Diretrizes e Bases da Educação Nacional foi decisória na medida em que fez referência à formação de profissionais ativos e reflexivos em setores específicos ${ }^{(2)}$.

Frente a isso, em 1999, foi criado pelo governo federal o Programa de Profissionalização dos Trabalhadores de Enfermagem para qualificar os profissionais inseridos nos serviços de saúde sem o preparo necessário. Este programa foi desenvolvido no contexto do trabalho, buscando também regularizar a situação dos trabalhadores em conformidade com a Lei no 7.498/1986 do Conselho Federal de Enfermagem, que extinguia o atendente de Enfermagem, visto que este profissional exercia atividades sem o devido preparo. Essa formação se fazia necessária essencialmente àqueles sem condições de acesso a cursos ofertados pelo mercado educacional ${ }^{(3)}$.

Visando a ampliar a oferta, fortalecer e qualificar a formação técnica em conformidade com os princípios e diretrizes do Sistema Único de Saúde (SUS), no ano 2000, foi criada a Rede de Escolas Técnicas de Enfermagem, a qual conta com 36 escolas técnicas e centros formadores distribuídos por todos os estados da federação ${ }^{(1)}$. Sua organização pedagógica pauta-se na metodologia da problematização, na integração ensino e serviço e na interdisciplinaridade.

A formação do técnico de Enfermagem vem sofrendo transformações também impulsionadas pelas Diretrizes Curriculares Nacionais para a educação profissional técnica de nível médio, que propõe, entre outros aspectos, a indissociabilidade entre educação e a prática social, com ênfase no fato de que a interdisciplinaridade deve ser assegurada no currículo e na prática pedagógica, visando à superação da fragmentação existente no processo de ensino ${ }^{(4)}$.

Entretanto, ainda existem algumas dificuldades na sua definição, considerando a multiplicidade de interpretações. Destaca-se, entre elas, a lógica racional que defende a construção do saber justificada unicamente pelo conhecimento; há também a interpretação de que a interdisciplinaridade é determinada pelo saber fazer e, por fim, a concepção predominante no Brasil que compreende a interdisciplinaridade para além do conhecer e do saber fazer, pois envolve também o aspecto afetivo, que ocorre por meio de atitudes capazes de promover o crescimento e a realização humana ${ }^{(5)}$.

A esta concepção de interdisciplinaridade acrescenta-se a convergência de todas as ciências humanas, levando a uma síntese na visão do homem e de sociedade ${ }^{(6)}$. Exige estrutura institucional flexível e novos conteúdos curriculares articulados em torno de problemas reais. Assim, quanto mais as disciplinas se aproximam do ensino profissionalizante, maior a relevância de assumir uma postura interdisciplinar de forma a facilitar a aprendizagem ${ }^{(7)}$.

A interdisciplinaridade vem sendo discutida no Brasil desde a década de 1970, com a compreensão de que, na sua função instrumental, recorre a um saber útil e utilizável para responder às questões e aos problemas sociais. Trata-se de uma atitude em torno do conhecimento, com ênfase nas relações humanas, a partir de uma prática pedagógica consistente e uma organização curricular apropriada ${ }^{(5)}$.

Entretanto, tem-se observado que ela ainda é pouco praticada, em razão, especialmente, da falta de docentes com esse conhecimento, uma vez que essa concepção de ensino se pauta na contextualização, problematização e na inter-relação de diferentes aspectos da vida pessoal, social e cultural ${ }^{(8)}$.

Ao considerar as novas tendências educacionais na formação do profissional de Enfermagem de nível médio frente aos anseios do mundo do trabalho, a presente pesquisa parte do questionamento sobre quais foram as propostas, os avanços e os desafios da implementação da interdisciplinaridade na formação técnica em Enfermagem no estado de São Paulo. O estudo tem como objetivo caracterizar os pontos e contrapontos no desenvolvimento da interdisciplinaridade na formação técnica em Enfermagem.

\section{MÉTODO}

\section{TIPO DE ESTUdo}

Trata-se de um estudo exploratório-descritivo com abordagem qualitativa realizado por meio de entrevistas a respeito das práticas interdisciplinares desenvolvidas no curso técnico em Enfermagem das escolas técnicas estaduais do estado de São Paulo.

\section{Cenário}

O local do estudo é uma instituição educacional do estado de São Paulo, que oferta o ensino profissional gratuito, composta por 223 unidades escolares, sob gestão da administração central, responsável por nortear o trabalho desenvolvido nas unidades escolares por meio de diretrizes específicas baseadas na legislação vigente do país e em consonância com as normas e diretrizes do regimento institucional. As escolas ofertam 150 cursos em diferentes eixos tecnológicos, sendo que 58 unidades escolares ofertam o curso técnico em Enfermagem, com uma oferta média de 1.865 vagas semestrais em 12 regiões administrativas por todo estado de São Paulo ${ }^{(9)}$. 
Em se tratando do curso técnico em Enfermagem, a estrutura curricular está organizada em quatro módulos, em que cada um corresponde a um semestre, com sua conclusão ao término de dois anos, com carga horária de 1.280 horas-aulas. Há uma certificação intermediária, como auxiliar em Enfermagem ao concluir os dois semestres, ou seja, dois módulos. As unidades escolares possuem parcerias com as instituições de saúde do município e região, de modo a garantir o estágio supervisionado aos alunos para a obtenção de competências inerentes à profissão, aproximação da teoria com a prática e incentivo do desenvolvimento de ações interdisciplinares na promoção da aprendizagem.

\section{DEFINIÇÃO DA AMOSTRA}

Para a definição amostral, foram selecionadas, por meio de sorteio, 12 escolas técnicas estaduais do estado de São Paulo, que ofertam o curso técnico em Enfermagem, sendo uma escola por região administrativa, esclarecendo que nesta etapa não houve recusa. Em cada uma das 12 unidades, foram convidados a participar do estudo o coordenador do curso em exercício e dois professores indicados pela coordenação e/ou direção da unidade escolar, sendo estes com pelo menos dois anos de atuação na unidade escolar. Os convidados foram contactados via e-mail para serem informados sobre o estudo e obtenção do acordo para participar ou não da pesquisa. Houve recusa de 18 professores na fase inicial do contato via e-mail; assim, foram realizados três novos sorteios na tentativa de obter o aceite dos integrantes das 12 unidades. Entretanto, em duas delas, houve retorno de apenas um docente e, quanto aos coordenadores, mesmo tendo concordado com o estudo e fornecido os dados de contato do docente, não conseguiram participar das entrevistas com a alegação de falta de tempo. A amostragem foi composta por 30 participantes.

\section{Coleta de dados}

As entrevistas foram agendadas com os participantes via telefone e realizadas por videochamadas por meio do WhatsApp. As entrevistas contaram com um roteiro semiestruturado, contendo questões sobre os dados de identificação e informação sobre o entendimento de interdisciplinaridade, as iniciativas realizadas para caminhar frente à interdisciplinaridade, avanços e desafios dessa prática. Foram gravadas e transcritas na íntegra para posterior análise.

\section{AnÁlise e TRATAMENTO dOS DADOS}

A análise da temática foi referenciada pela técnica proposta por Braun e Clarck $^{(10)}$ e consiste em um método analítico qualitativo que permite identificar, analisar e relatar o tema estabelecido na pesquisa, interpreta vários aspectos dentro dos dados coletados, possibilitando apresentar os conteúdos e o significado de padrões (temas) nos dados coletados ${ }^{(10)}$.

A operacionalização da análise temática ocorre em seis fases que permitem sucessivas aproximações com os dados.
$\mathrm{Na}$ primeira fase, realiza-se a familiaridade com os dados, conseguida pela imersão neles, por meio de leituras repetidas a fim de se aproximar da profundidade e amplitude do conteúdo ${ }^{(10)}$.

A segunda fase envolve a produção de códigos iniciais a partir dos dados. Esses códigos representam o conteúdo semântico ou latente que se refere ao segmento ou elemento mais básico do dado. A terceira fase inclui a procura por temas, é desenvolvida a partir da lista de códigos e abrange a triagem dos diferentes para compor temas potenciais. $\mathrm{Na}$ finalização, houve coleção de temas e subtemas. $\mathrm{Na}$ fase quatro, é momento de revisitar os temas, engloba-se o refinamento e ponderam-se os critérios de homogeneidade interna e heterogeneidade externa para criação de mapa temático. $\mathrm{Na}$ sequência, fase cinco, os temas são definidos e nomeados, ou seja, é identificada a essência do assunto de cada tema. $\mathrm{Na}$ última fase, inicia-se a análise e a escrita do relatório acadêmico ${ }^{(10)}$.

\section{AsPeCtOS ÉTICOS}

O projeto foi submetido ao Comitê de Ética em Pesquisa com Seres Humanos da instituição proponente recebendo parecer favorável, sob no. 3.312.041/2019, de acordo com a Resolução no 466/2012, do Conselho Nacional de Saúde, no que tange aos princípios éticos que envolvem pesquisas sociais com seres humanos. Os participantes foram esclarecidos quanto à finalidade do estudo e, após o aceite, assinaram o Termo de Consentimento Livre e Esclarecido, escanearam e enviaram ao e-mail do pesquisador. Com o objetivo de manter o anonimato dos participantes, os mesmos foram organizados por siglas, em que $\mathrm{P}$ representa professor, $\mathrm{C}$ coordenador e $\mathrm{C} / \mathrm{P}$ coordenador e professor, precedidas pelos números de 1 a 30, representando o número total de participantes.

\section{RESULTADOS}

Entre o total de participantes do estudo (30), a maioria 27 (90,0\%) é do sexo feminino, 22 (73,3\%) são professores, sete $(23,3 \%)$ acumulam a função de coordenador e professor e um $(3,3 \%)$ é apenas coordenador. Quanto ao tempo de atuação profissional na instituição de ensino, 10 (33,0\%) possuem entre 2 a 5 anos de atuação, sete $(23,0 \%)$ entre 7 a 12 anos, sete $(23,0 \%)$ entre 14 a 17 anos e seis $(20,0 \%)$ entre 18 a 24 anos. Todos os entrevistados possuem graduação em Enfermagem, 27 (90,0\%) possuem pós-graduação lato sensu na área e (20,0\%) mestrado na área da Enfermagem ou da Educação.

A análise dos dados obtidos nas entrevistas com docentes e coordenadores do curso técnico em Enfermagem permitiu a elaboração de três temas: direcionamento institucional, o caminho da interdisciplinaridade e a compreensão do conceito, sendo que cada um deles apresenta aspectos que favorecem e aspectos que dificultam a interdisciplinaridade, sendo esses considerados como pontos e contrapontos dessa implementação na formação técnica em Enfermagem (Figura 1). 


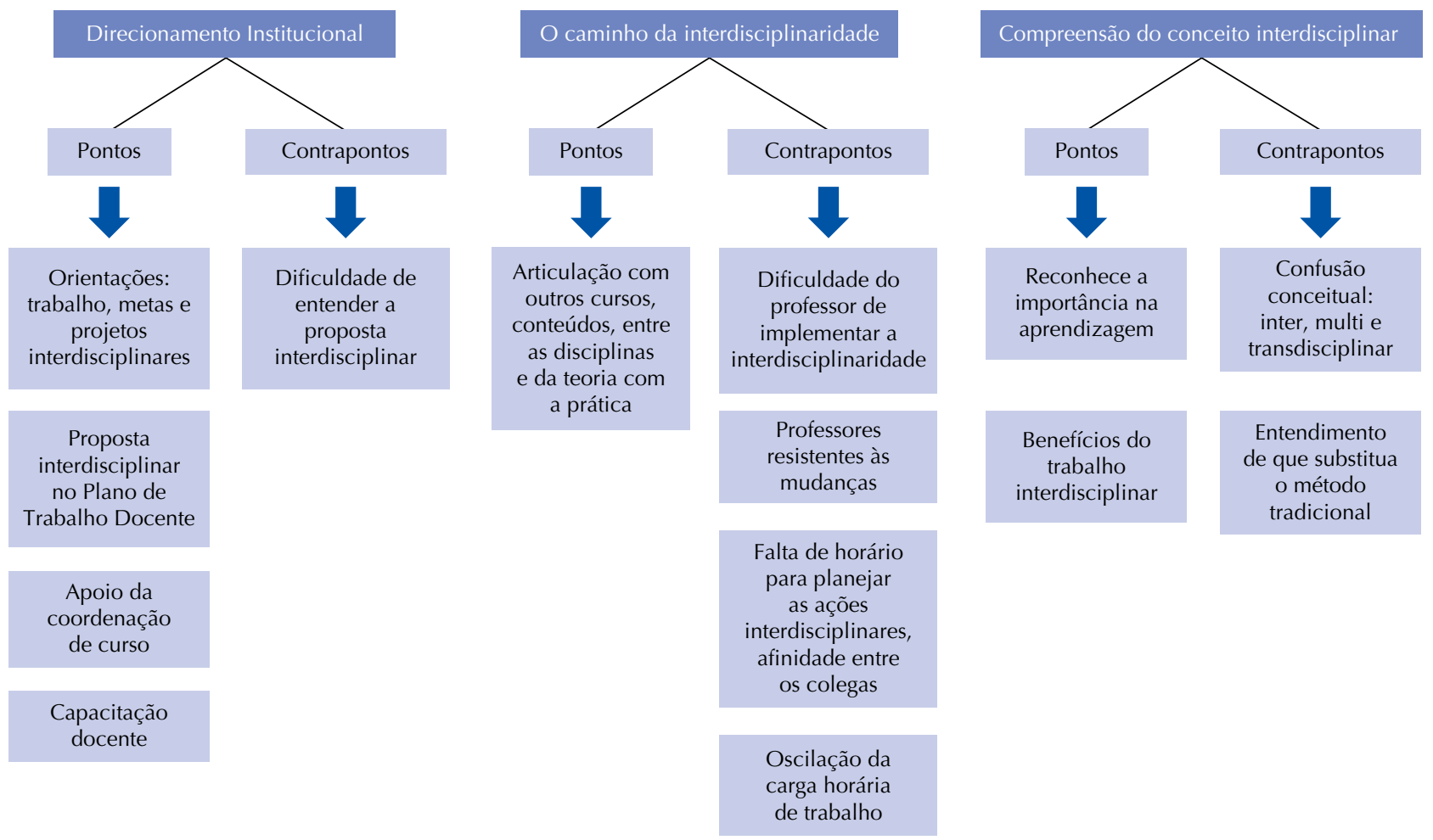

Figura 1 - Distribuição dos temas e subtemas de acordo com os pontos e contrapontos.

\section{DiRECIONAMENTO INSTITUCIONAL PARA IMPLANTAÇÃO DA INTERDISCIPLINARIDADE}

Nas entrevistas, revela-se que há um direcionamento institucional na busca de um trabalho interdisciplinar, uma vez que há preocupação em emanar as orientações e definir as metas para desenvolver projetos articulados com outros cursos, além de solicitação para que sejam colocadas iniciativas de interdisciplinaridade no plano de trabalho docente. Existe, ainda, uma coordenação pedagógica que apoia esse desenvolvimento por meio de reuniões, cursos semestrais, diálogo e conversa.

Dispõe de um centro de capacitação do corpo docente para a formação continuada dos profissionais que atuam nas escolas, mantendo-os atualizados para o desenvolvimento curricular em atendimento ao plano de curso e ao projeto pedagógico da unidade escolar.

$N a$ verdade, nós temos metas de ter pelo menos um projeto para trabalhar a interdisciplinaridade $(3 \mathrm{C} / \mathrm{P})$.

A orientação da instituição é para colocarmos dentro do plano de trabalho docente...e ai a gente tem que desenvolver junto com os outros cursos para todo mundo participar (7P).

[...] professores são orientados nas reunióes pedagógicas, já começa com as instruções nas reunióes de curso e tem as demais em continuidade (12P).

[...] se temos alguma dúvida como trabalhar, pegamos o plano de aula e vemos como a matéria vai ser trabalhada (19P).

Entretanto, nesta trajetória, os entrevistados apontam para dificuldades inerentes a este processo, uma vez que, para eles, as orientações são poucas e vagas, necessitando serem trabalhadas mais efetivamente com o apoio institucional da equipe escolar. Desta forma, as informações ficam perdidas no projeto, não acontecendo na prática.

Durante o planejamento do semestre, conversamos, fazemos um projeto em relação a isso, mas, assim, tem ficado muito no papel! (4P).

Eles dão as orientações, mas ficam meio superficiais e, na prática, não se consegue implantar não... é muito difícil de conciliar todos os professores (30P).

Não recebemos essas informações de uma forma tão clara. Para trabalharmos os projetos interdisciplinares, a meu ver, deviam ser mais divulgados, mais esclarecidos (8P).

[...] acho que poderia ter capacitação, uma formação, um curso para os professores a respeito das atividades interdisciplinares... Houve algumas orientações, mas foram poucas (10P).

\section{CAMINHO dA INTERDISCIPLINARIDADE PERCORRIDO PELOS DOCENTES}

Para a efetivação da interdisciplinaridade, os entrevistados realizam a articulação com outros cursos do Ensino Médio, articulam conteúdos e disciplinas, os componentes de um módulo, além de apontarem para a articulação da teoria e prática.

Nós temos um projeto junto com o curso de Evento da escola, que pretende desenvolver a questão da hospitalidade dentro do ambiente hospitalar (13P). 
Temos que trabalhar também com a interdisciplinaridade os próprios cursos da escola, o de Informática e Gestão (2C/P).

Fazemos um ciclo de palestras na escola envolvendo todos os alunos sobre atendimento de primeiros socorros (9P).

Eu busco me relacionar com a professora da teoria para que eu possa auxiliar e facilitar o aprendizado da prática (17P).

Como contraponto à trajetória de construção, os professores indicam que encontraram dificuldades, como resistência às mudanças, por considerarem uma atividade trabalhosa. Alegam também que faltam horários em comum para o planejamento e realização das atividades de forma integrada, falta de afinidade e de consenso entre os colegas e, nem sempre, a atribuição de aulas ocorre de forma regular, ou seja, não mantém a carga horária do semestre anterior, tornando o processo desgastante, desmotivante e exaustivo.

Alguns professores são mais resistentes, eles querem aulas mais tradicionais para dar conta do conteúdo. Usar a interdisciplinaridade eles acham muito trabalhoso (29P).

Olha, para os professores, alguns têm algumas facilidades, mas tem uns que têm bastante dificuldade. Que não entendem! Principalmente os professores mais antigos (3CP).

O horário que eu posso, o outro professor não pode né! E também tem o curso que é semestral e cada atribuição de aula pode mudar para cada professor (12P).

[...] eu tive uma carga reduzida, devido à atribuição de aulas $e$, como atribuição é sempre uma caixinha de surpresa, quando a gente pega mais, tem mais tempo para se dedicar (12P).

[...] muitas vezes por falta de afinidade com o próprio colega (18P).

Eàs vezes fica truncado, até porque, quando a gente pretende relacionar duas teorias de uma forma mais efetiva, mais aprofundada, nem sempre o colega tem a mesma visão que a gente $(21 \mathrm{C} / \mathrm{P})$.

É desgastante! É desmotivante exaustivo, porque a maioria dos colegas não tem a visão e eles não se dedicam (21C/P).

\section{COMPREENSÃO DO CONCEITO DE INTERDISCIPLINARIDADE}

Os entrevistados compreendem a importância da interdisciplinaridade, considerando que, com sua implementação, o professor e o aluno aprendem, ampliam a visão, agregam conhecimento, aprendem a trabalhar em grupo e fazem com que o aluno aprenda o que é um projeto, evitam repetições de conteúdos, permitindo a correlação da teoria com a prática. $A$ interdisciplinaridade ajuda tanto a construir o seu conhecimento... fazendo junto eu aprendo e o aluno também (5P).

Olha eu acho que é superimportante a interdisciplinaridade, porque uma matéria de uma disciplina está relacionada com a outra (28C).

[...] agregar os conhecimentos e aprender a trabalhar em equipe e que ele vai sair dali, vai trabalhar com outros profissionais (10P).

[...] faz com que o aluno realmente entenda o que é um projeto, como realizar esse projeto junto com outros componentes e junto com outros cursos (10P).
Eu acho que, através da interdisciplinaridade, o aluno consegue abranger, ter maior conhecimento que as aulas saiam do tradicional, aqui tentamos fazer juntamente com a parte prática e trazer outros profissionais $(16 \mathrm{C} / \mathrm{P})$.

Entretanto, eles consideram que há confusão conceitual quando se trata da interdisciplinaridade, transdisciplinaridade e multidisciplinaridade. Acreditam que a interdisciplinaridade deva existir de forma concomitante e não em substituição ao método tradicional.

Ainda têm muitas professoras que tem duividas e confundem muito a inter com a transdisciplinaridade (3C/P).

Eu também acho que não dá para tirar o modo tradicional... Então ela [Interdisciplinaridade] tem que ser trabalbada junto com as disciplinas fragmentadas (4P).

\section{DISCUSSÃO}

Frente aos dados contidos nas entrevistas com docentes e coordenadores do curso técnico em Enfermagem, foram tomados, como ponto de partida, os indicativos de avanços relacionados à implementação da interdisciplinaridade e, como contrapontos, os aspectos que dificultam sua implementação, que se referem ao direcionamento institucional, no caminho da interdisciplinaridade percorrido pelos docentes, e à compreensão do conceito.

Os pontos e contrapontos, no entanto, não são vistos como dicotômicos, mas como aspectos que se afirmam e se negam reciprocamente e que se constituem em mola propulsora para as mudanças necessárias, uma vez que para duas características serem opostas, elas precisam ter algo em comum e permanecerem ativamente interconectadas ${ }^{(11)}$. Nesta perspectiva, considerando a complexidade do objeto de estudo, o qual caminha entre avanços e desafios inerentes aos processos de mudanças, são tecidos reflexões e aprofundamentos com vistas a ampliar a compreensão do movimento da interdisciplinaridade no curso técnico em Enfermagem.

No que se refere ao direcionamento institucional para promover a interdisciplinaridade, um importante aspecto a ser considerado no sucesso da implantação de processos de mudanças, visto que é a quem cabe proporcionar a estrutura necessária para o seu desenvolvimento, observa-se que isso ocorre na medida em que oferecem capacitações e orientam os caminhos, por meio dos documentos oficiais e acompanhamento das ações pedagógicas. Entretanto, essas ações são consideradas como insuficientes, uma vez que também contam com aspectos estruturais que dificultam o trabalho nesta lógica, pois falta, essencialmente, a necessária flexibilização para a inserção de conteúdos articulados a partir de problemas reais ${ }^{(7)}$.

Compreende-se que a matriz curricular do curso precisa ser construída de forma flexível e orientada para que o estudante possa enfrentar os desafios da aprendizagem, o que se concretiza quando existe um espaço de discussão interdisciplinar que propicia um ensino direcionado para esta prática, a partir de problemas reais. Dessa forma, quando o estudante é exposto à atividade interdisciplinar, torna-se possível a percepção de que existe um objetivo em comum a ser atingido entre as disciplinas. Evidencia-se, assim, uma nova atitude diante do ensino, em que o currículo é pensado na sua integralidade 
para ser aplicado em todos os momentos do ano letivo, sempre direcionado por ações institucionais planejadas ${ }^{(7,12)}$.

Assim, se reconhece que a contratação docente com carga horária parcial ou temporária é um dificultador desse processo; entretanto, essa é uma condição frequente entre as escolas formadoras de técnicos em Enfermagem. Dificuldades semelhantes para a implementação da interdisciplinaridade são encontradas pelas universidades brasileiras. Mesmo com esforços significativos na sua promoção, a organização e funcionamento na lógica disciplinar encontram-se fortemente estabelecidos, depreendendo-se a necessidade de criar condições mais adequadas para a efetivação dessa prática ${ }^{(13)}$. Nesta perspectiva, é importante resgatar que a interdisciplinaridade é construída por meio de múltiplas possibilidades de encontros entre os atores envolvidos no processo de ensino e aprendizagem, o que implica ter um docente com vínculo instrucional que lhe permita capacitação, dedicação e envolvimento efetivo nas ações educativas desenvolvidas.

A partir da consideração de que a palavra de ordem na prática interdisciplinar é o diálogo, o modo como ele acontece define tal prática como produtiva ou como problemática $^{(13)}$, sendo possível verificar que esses dois aspectos ocorrem no cotidiano dos entrevistados ao percorrer o caminho da interdisciplinaridade. Por um lado, eles buscam articular conteúdos, disciplinas e módulos, além da articulação da teoria com a prática e, por outro lado, existe resistência às mudanças e falta de estrutura para sua efetivação. Coaduna-se, assim, que a interdisciplinaridade se caracteriza pelas trocas de informações, integrações entre as disciplinas e depende da relação interpessoal com a equipe ${ }^{(5,14)}$.

No que tange às dificuldades, essas incluem a desarticulação da comunicação entre os docentes para a inserção da interdisciplinaridade no currículo, o que nos direciona para uma discussão relacionada à matriz curricular. É preciso superar o currículo organizado por disciplinas e avançar em relação à justaposição das áreas, que não contam com a devida articulação dos conteúdos, ou seja, há interação apenas para a resolução de casos específicos, pontuais, estipulados por cada disciplina ${ }^{(15)}$.

Quanto à organização curricular, embora no curso em pauta o currículo conte com organização por módulos, observa-se que os conteúdos, muitas vezes, são desenvolvidos de forma isolada, com poucas possibilidades de encontro e desenvolvimento conjunto.

Nas Orientações Educacionais Complementares aos Parâmetros Curriculares Nacionais, encontra-se descrito que a interdisciplinaridade deve ser constantemente trabalhada entre os professores; porém, divergências entre eles podem dificultar essa prática, o que ocorre com frequência, uma vez que a proposta pedagógica de articulação dos conhecimentos, por meio da interdisciplinaridade, não está clara para os docentes na sua prática escolar, assim como foi observado entre os entrevistados do presente estudo ${ }^{(16)}$.

Outro aspecto a ser considerado na implementação da interdisciplinaridade refere-se à compreensão conceitual por parte dos entrevistados. Nesta perspectiva, ao considerar que os docentes e coordenadores atuantes no ensino técnico de enfermagem não foram formados sob essa lógica, é de se esperar que as instituições de ensino promovam capacitações de forma coesa e abrangente, além de proporcionar estrutura para que essa nova lógica ocorra a contento, por meio da articulação das disciplinas e dos múltiplos saberes, necessários ao enfrentamento de situações complexas ${ }^{(17)}$.

A tentativa de se implementar a prática interdisciplinar acaba acontecendo por meio de propostas desprovidas de relação interdisciplinar, pois se limitam à execução de atividades em conjunto, demonstrando a necessidade de capacitar professores para a efetividade da interdisciplinaridade ${ }^{(18)}$. Isto mostra a necessidade de interação entre os docentes e a instituição para estruturar sua prática pedagógica, o trabalho em grupo e a ressignificação da proposta política pedagógica, para que seja implementada a interdisciplinaridade na ação de todos envolvidos no processo, o que demanda um engajamento do professor, quando se pensa em um currículo integrado.

A interdisciplinaridade contribui para a formação profissional de modo a propiciar uma assistência ao ser humano de forma individual e coletiva. Os desafios no ensino da Enfermagem remetem a pensar nas mudanças do processo de aprender, os instrumentos e as estratégias de ensino na resolução de problemas, para que sejam baseados no contexto interdisciplinar. Nesse sentido, o desafio está em compreender a complexidade do cuidado humano, alinhando-se à proposta interdisciplinar no exercício da profissão ${ }^{(4)}$.

É relevante também considerar que, para que ocorra a integração de disciplinas, precisa-se de sujeitos dispostos a construir uma perspectiva integradora, incorporar uma inovação ao cotidiano e também a estarem abertos às mudanças nas práticas pedagógicas arraigadas no imaginário dos docentes, o que de fato não se mostra como uma ação fácil de se concretizar, conforme observado nesse estudo, pois existe uma resistência dos professores para essas mudanças ${ }^{(19)}$. Reforça-se, portanto, que a superação da fragmentação do conhecimento requer uma transformação na escola, no currículo, na postura do professor e clareza do significado do conceito interdisciplinar, como o domínio dos saberes curriculares e pedagógicos ${ }^{(20)}$. Por essa razão, fazem-se necessárias mudanças paradigmáticas que, por certo, demandam tempo, capacitação docente e abertura dos mesmos para a incorporação de novas visões sobre o processo de ensino e aprendizagem, além de investimento institucional nesta direção.

Exige-se, assim, um constante canal para o diálogo e para a valorização das pessoas na sua totalidade, por meio do reconhecimento de suas potencialidades e do respeito à dignidade. Por meio do diálogo, ocorre o resgate da generosidade, a abertura de espaço para o outro, o rompimento das barreiras internas de cada pessoa, o que culmina na promoção de mudanças ${ }^{(21)}$.

Neste processo deve-se levar em conta a importância do protagonismo dos envolvidos e o poder de autonomia de cada um do grupo, o que vai ao encontro de uma gestão compartilhada e de lideranças distribuídas, com ênfase nas relações humanas, pautadas no princípio da diversidade e na forma de ser e estar no mundo de cada integrante, com vistas a promover o sentimento de pertencimento ${ }^{(22)}$.

No presente estudo, coloca-se como limitação o fato de ter sido realizado em uma única instituição. Embora conte 
com unidades distribuídas em todo o estado de São Paulo, ela apresenta características específicas na sua estrutura e organização. Acredita-se, entretanto, que os resultados contribuem com reflexões acerca de uma temática relevante para o contexto da formação em saúde e, mais especificamente, para a formação do técnico de Enfermagem. Pode-se, assim, obter avanços na formação de profissionais em consonância com as necessidades do mundo do trabalho.

\section{CONCLUSÃO}

Ao analisar os pontos e contrapontos da interdisciplinaridade no curso técnico em Enfermagem, a partir da perspectiva de docentes e coordenadores, constatam-se aspectos relacionados ao direcionamento institucional, à implementação pelos docentes e ao conceito da interdisciplinaridade.

A instituição realiza orientações para o trabalho interdisciplinar e define metas para projetos articulados a outros cursos e conta com uma coordenação pedagógica que dá apoio aos docentes na construção desta lógica. Entretanto, apontam para a insuficiência da capacitação do corpo docente para que essa prática se efetive.

$\mathrm{Na}$ prática docente, há um esforço para a articulação com outros cursos ofertados nas escolas, no que tange aos conteúdos das disciplinas, aos componentes de um módulo e à teoria e prática. Como contraponto, os professores encontram dificuldades para planejar e compartilhar as atividades com outros docentes, devido à forma de contratação com carga horária parcial, além da resistência às mudanças, falta de afinidade e de consenso entre os professores.

Os entrevistados compreendem a interdisciplinaridade como importante, considerando que com isso o professor e o aluno aprendem, permitindo uma visão ampliada, que agrega conhecimento, promove o trabalho em grupo e evita repetições de conteúdos. Observa-se uma confusão conceitual, principalmente frente ao que se entende por interdisciplinaridade, transdisciplinaridade e multidisciplinaridade.

Frente aos pontos e contrapontos encontrados nas falas dos docentes, depreende-se a necessidade em avançar nesta construção, por meio de sua implementação no contexto da formação do técnico de Enfermagem e de constantes reflexões sobre as mudanças realizadas, com vistas à sua contínua reconstrução.

São necessários, portanto, estudos que também busquem verificar a percepção dos técnicos de Enfermagem sobre a sua formação, com vistas à complementariedade dos resultados aqui apresentados, além de outros em realidades distintas, para que seja possível o enfrentamento dos desafios impostos a essa formação.

\section{RESUMO}

Objetivo: Caracterizar os pontos e contrapontos no desenvolvimento da interdisciplinaridade na formação técnica em Enfermagem. Método: Estudo exploratório-descritivo com abordagem qualitativa realizada por meio de entrevistas com 30 docentes e coordenadores de cursos técnicos em Enfermagem de 12 diferentes regiões do estado de São Paulo. A análise dos dados foi de conteúdo temática. Resultados: No que se refere à temática de direcionamento institucional, constatou-se que, embora existam iniciativas para promover a interdisciplinaridade, uma vez que há capacitação docente e definição de metas para articulação com outros cursos e para o trabalho em conjunto entre os docentes das disciplinas, estas ainda são vagas e pouco efetivas. Na temática, implementação da interdisciplinaridade pelos docentes, verifica-se que eles buscam diferentes formas de integração, mas esbarram na estrutura curricular, na forma de contratação docente e na resistência às mudanças. Sobre a compreensão conceitual, há o reconhecimento de aspectos relevantes do seu significado; porém, admitem a existência de limites. Conclusão: A instituição define uma trajetória visando à interdisciplinaridade, os docentes buscam percorrer o caminho de sua implementação, porém encontram entraves estruturais, pouca compreensão conceitual e resistência a mudanças. Depreende-se que são necessários esforços para avançar na implementação curricular na lógica interdisciplinar.

\section{DESCRITORES}

Práticas Interdisciplinares; Educação Técnica em Enfermagem; Capacitação de Recursos Humanos em Saúde.

\section{RESUMEN}

Objetivo: Caracterizar los puntos y contrapuntos en el desarrollo de la interdisciplinaridad en la formación técnica en Enfermería. Método: Estudio exploratorio-descriptivo con abordaje cualitativa realizada por medio de entrevistas con 30 docentes y coordinadores de cursos técnicos en Enfermería de 12 diferentes regiones de la provincia de São Paulo. El análisis de los datos fue de contenido temático. Resultados: En lo que concierne al tema de direccionamiento institucional, se verificó que, aunque existan iniciativas para promover la interdisciplinariedad, una vez que hay capacitación a los docentes y definición de metas para articulación con otros cursos y para el trabajo en equipo entre los docentes de las disciplinas, todavía son imprecisas y poco efectivas. En el tema implementación de la interdisciplinariedad por los docentes se verificó que buscan diferentes formas de integración, pero encuentran obstáculos en la estructura curricular, en la manera de contratar a los docentes y en la resistencia a cambios. Acerca de la comprensión conceptual, existe el reconocimiento de aspectos relevantes de su significado, pero se admite la existencia de límites. Conclusión: La institución define una trayectoria que tiene como objetivo la interdisciplinariedad, los docentes buscan su implementación, pero encuentran barreras estructurales, poca comprensión conceptual y resistencia a cambios. Se concluye que esfuerzos son necesarios para avanzar en la implementación curricular en la lógica interdisciplinar.

\section{DESCRIPTORES}

Prácticas Interdisciplinarias; Graduación en Auxiliar de Enfermería; Capacitación de Recursos Humanos en Salud.

\section{REFERÊNCIAS}

1. Machado MH, Ximenes Neto FRG. The Management of work and education in Brazil's Unified Health System: thirty years of progress and challenges. Cienc Saúde Colet. 2018;23(6):1971-80. https://doi.org/10.1590/1413-81232018236.06682018

2. Vieira AMDP, Souza Junior A. A educação profissional no Brasil. Interacções. 1996;12(40):152-69. https://doi.org/10.25755/int.10691 
3. Kurebayashi LF, Mecone MC, Matos FG, Mendoza IY, Monteiro BA, Pinho PG, et al. [Amendment proposals concerning the nursing professional practice law, n. 7.498/86]. REME Rev Min Enferm [Internet]. 2008 [cited 2020 Jun 2];12(4):573-9. Available from: http:// www.reme.org.br/artigo/detalhes/303

4. Corrêa AK, Sordi MR. The secondary technical-professional education in the sus and the teacher training policy. Texto Contexto Enferm. 2018;27(1):e2100016. https://doi.org/10.1590/0104-07072018002100016

5. Perez OC. O que é interdisciplinaridade? Definições mais comuns em artigos científicos brasileiros. Interseções. 2018;20(2):454-72. https://doi.org/10.12957/irei.2018.39041..

6. Silva MO. A interdisciplinaridade como uma possibilidade no processo de ensino: aprendizagem da educação profissional de nível tecnológico para o mundo do trabalho. Rev Bras Educ Prof Tecnol. 2017;2(13):13-30. https://doi.org/10.15628/rbept.2017.4766

7. Japiassu H. Interdisciplinaridade e patologia do saber. Rio de Janeiro: Imago; 1976.

8. Silva DM, Araújo FO, Ferreira RG. [Interdisciplinarity: reflections on pedagogical practices in integrated middle school]. Rev Bras Educ Prof Tecnol. Portuguese. 2020;1(1):1-20. https://doi.org/10.15628/rbept.2020.8814

9. São Paulo (Estado). Centro Paula Souza.. Localização das Etecs [Internet]. São Paulo: Centro Paula Souza; [2020] [cited 2020 Jun 2]. Available from: http://www.portal.cps.sp.gov.br/etec/escolas/

10. Braun V, ClarkeV. Using thematic analysis in psychology. Qual Res Psychol. 2008;3(2):77-101. https://doi.org/10.1191/1478088706qp063oa

11. Marquit E. Contradições na dialética e na lógica formal. Princípios Rev Teór Polít Inf [Internet]. 1996 [cited 2020 Jun 2];43:58-68. Available from: http://www.grabois.org.br/cdm/colecao-principios/151718-44623/1996-11-01/contradicoes-na-dialetica-e-na-logica-formal

12. Bilar JG, Bortoluzzi LZ, Coutinho RX. [Interdisciplinarity and professional practice: challenges in integrated secondary education]. Rev Eletr Cient Ensino Interdisc. 2018;4(11):397-409. Portuguese. https://doi.org/10.2192/recei.v4i11.2732

13. Pereira SP, Garcia CA, Kanaane R, Fernandez SA, Lima R. Empreendedorismo - utilizando a ABProj (Aprendizagem Baseada em Projetos) na educação profissional. Anais do XII Workshop de Pós-Graduação e Pesquisa do Centro Paula Souza; 3-5 out 2017; São Paulo, SP. São Paulo: Centro Paula Souza; 2017. p. 623-33.

14. Fazenda IC. Integração e interdisciplinaridade no ensino brasileiro: efetividade ou ideologia. 6a ed. São Paulo: Loyola; 2011.

15. Fiorin PB, Salamoni B, Motta GA, Balsissera FG, Zaneti IC, Magalhães CR. The interdisciplinary education in healthcare: prospects for the multiprofissional development. Rev Didática Sist [Internet]. 2014 [cited 2020 Jun 2];16(2):30-43. Available from: https://periodicos.furg. br/redsis/article/view/4551

16. Berti VP, Fernandez C. Interdisciplinaridade sob olhares distintos. In: Anais do VI Encontro Nacional de Pesquisa em Ensino de Ciências; 2007; Florianópolis, SC. Belo Horizonte: Abrapec; 2007. p. 736-47.

17. Freire LA, Almeida RS. [Interdisciplinarity as knowledge integration: overcoming the fragmentation of knowledge]. Percurso Acad. 2017;7(14):436-52. Portuguese. https://doi.org/10.5752/P.2236-0603.2017v7n14p436-452

18. Satolo VP, Bernardo CH, Lourenzani AE, Morales AG. A historical and conceptual overview of interdisciplinary research: an analysis of interdisciplinary graduate courses. Educ Rev. 2019;35:e185294. https://doi.org/10.1590/0102-4698185294

19. Lima VV, Ribeiro EC, Padilha RQ, Mourthé Júnior CA. Challenges in the education of health professionals: an interdisciplinary and interprofessional approach. Interface (Botucatu). 2018;22(2):1549-62. https://doi.org/10.1590/1807-57622017.0722

20. Rios DR, Sousa DA, Caputo MC. [Interprofessional and interdisciplinary dialogues in university extension: a pathway towards incorporating a broader concept of health into academic education]. Interface (Botucatu). 2019;23:e180080. Portuguese. https://doi.org/10.1590/ interface. 180080

21. Mendonça KM, Moraes DC. Métodos consensuais de solução de conflitos: a produção dialógica para uma cultura de paz. Ver EPOS [Internet]. 2016 [cited 2020 Nov 18];7(2):73-84. Available from: http://pepsic.bvsalud.org/scielo.php?script=sci_arttext\&pid=S2178-700X2 $016000200006 \& \operatorname{lng}=$ pt\&nrm=iso\&tlng=pt

22. Cardelli J, Duhalde M, Maffei L. Educação para o século XXI. São Paulo: Instituto Polis; 2003. 